\title{
Indication of a dilatant bed near Downstream B Camp, Ice Stream B, Antarctica
}

\author{
S. R. Atre ANd C. R. Bentley \\ Geophysical and Polar Research Center, University of Wisconsin- Madison, Madison, WI 53706, U.S.A.
}

\begin{abstract}
Phases of seismic P-wave reflections from the bed of Ice Stream B at a site on its ice plain have been examined. The survey comprised a $36 \mathrm{~km}$ line at a shallow angle $\left(18^{\prime}\right)$ to ice movement and four $3.6 \mathrm{~km}$ cross lines. Reversed-phase and unreversed-phase reflections each characterize about half the bed. The corresponding zones can be correlated in stripes quasi-parallel to icc movement. We take this as support for a model previously developed that relates the zones to different types of subglacial sediment dragged along by the ice. There is also evidence for patches of pooled water.
\end{abstract}

\section{INTRODUCTION}

The University of Wisconsin-Madison has conductcd seismic experiments during four field seasons on Ice Streams B and C, West Antarctica. The objective of these experiments was to investigate the basal conditions beneath these ice streams and how they might affect their dynamic behavior. We have already reported on the characteristics of the ice/bed interface beneath stations Upstream B (UpB) and Upstream C, centrally located on the two ice strcams, as revealed by the phases of seismic P-wave reflections (Atre and Bentley, 1994). Here, we report on a similar investigation at Downstream $B$ station (DnB) on the ice plain of Ice Stream B (Fig. 1).

\section{FIELD WORK}

During the 1987-88 ficld season at DnB, high-resolution P-wave reflection data were collected by S.T. Rooney along a $36 \mathrm{~km}$ protile nearly parallel to the direction of icc movement (the $Z$ line) and four $3.6 \mathrm{~km}$ transverse profiles (the $\mathrm{V}, \mathrm{W}, \mathrm{X}$ and $\mathrm{Y}$ lines) (Fig. 2). For all experiments, the receiving spread was $690 \mathrm{~m}$ long with 24 gcophones spaced $30 \mathrm{~m}$ apart. Sources were $0.15 \mathrm{~kg}\left(\frac{1}{3} \mathrm{lb}\right)$ or $0.45 \mathrm{~kg}$ (1lb) explosive charges detonated in boreholes $14-18 \mathrm{~m}$ decp. Amplifiers had a flat frequency response without phase shift within the frequency band employed $(50-450 \mathrm{~Hz})$, which extended well beyond the signal frequencics $(200-300 \mathrm{~Hz})$. Detailed descriptions of the data collection and reduction can be found in Blankenship and others (1987), Rooney and others (1987), Rooney (1988) and Atre 1990). For this study of phases, we have not carried out any stacking, move-out corrections or any other processing that could conceivably distort the phase information. Instead, we rely on visual inspection of individual scismograms. All the seismograms presented here are displayed with the same gain and all were recorded from $0.45 \mathrm{~kg}$ charges.

\section{REFLECTION PHASES}

For a detailed discussion of acoustic impedance the product of density and $\mathrm{P}$-wave specd), the condition for P-wave phase reversal, the process of identifying the phase, and the justification for using real (rather than complex) impedances in both ice and bed, see Atre and

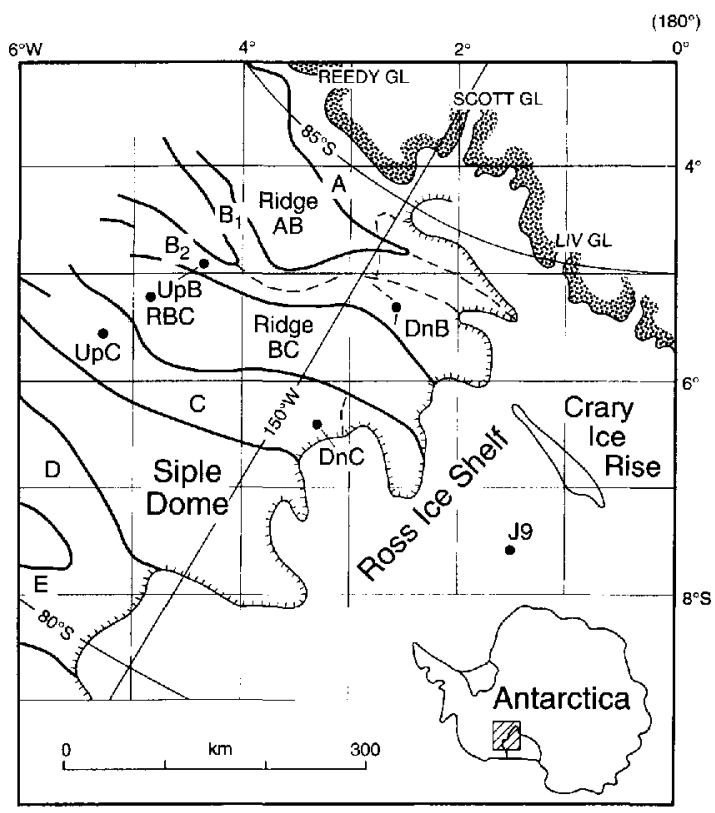

Fig. 1. Map of the Siple Coast ice streams (shaded) showing the location of stations Downstream $B(D n B)$, Upstream $B(U p B)$ and Upstream $C(U p C)$. 


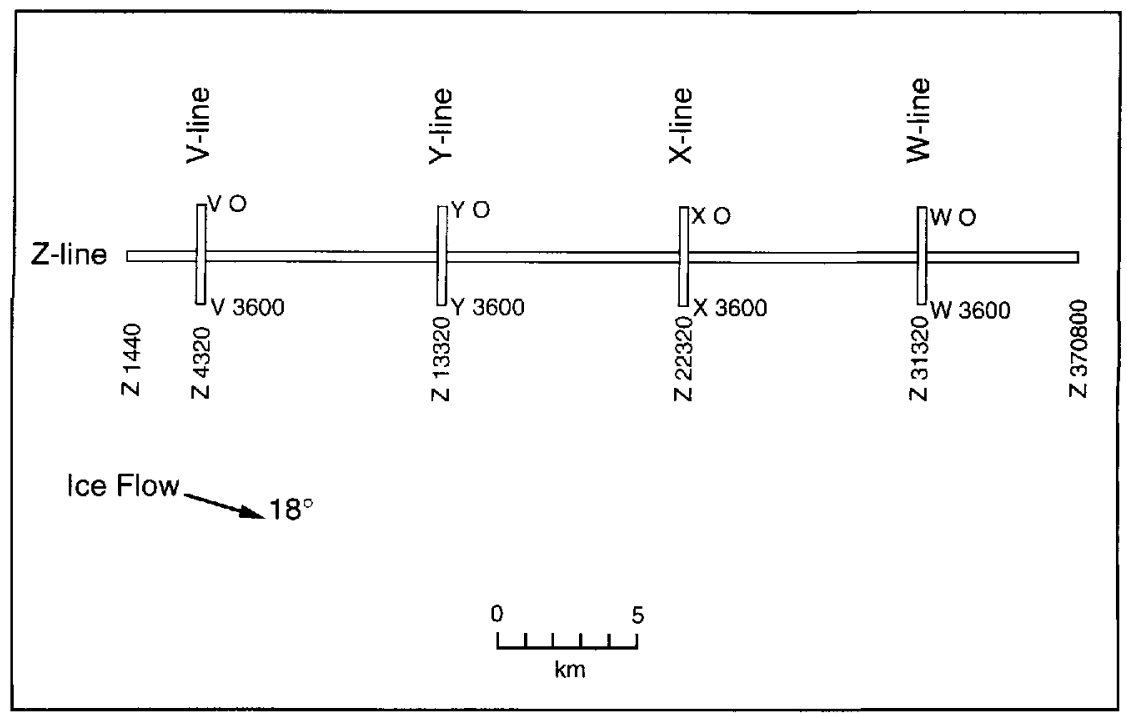

Fig. 2. Diagram of the seismic survey lines at DnB. The arrow shows the direction of ice movement.

Bentley (1993). In bricf, it turns out that the acoustic impcdances in the ice and the dilated bed are nearly the same. Since the condition for a phase reversal is that the impedance in the bed is less than in the ice, small variations in physical characteristics of the bed can make the difference between a phase reversal and no phase reversal in a reflection.

We show here some seismograms illustrating various characteristics of the reflection. On these scismograms, each horizontal line shows the ground motion detected by one of a linear array of seismometers. Upward deflection of the trace is indicative of upward movement of the ground. Time increases from left to right. 'The first signal to appear is the direct $\mathrm{P}$ wave through the ice; the second strong signal, a few hundred milliseconds later, is the reflection from the bed. The scismogram in Figure 3 provides a typical example of the reversed-phase relationship between direct and reflected P-wave arrivals that is clearly observed, with high signal-to-noisc ratio, on most of the records. The reversed phase implies that the acoustic impedance of the bed is less than that of the ice ("low-impedance bed"). Another reflection that can be

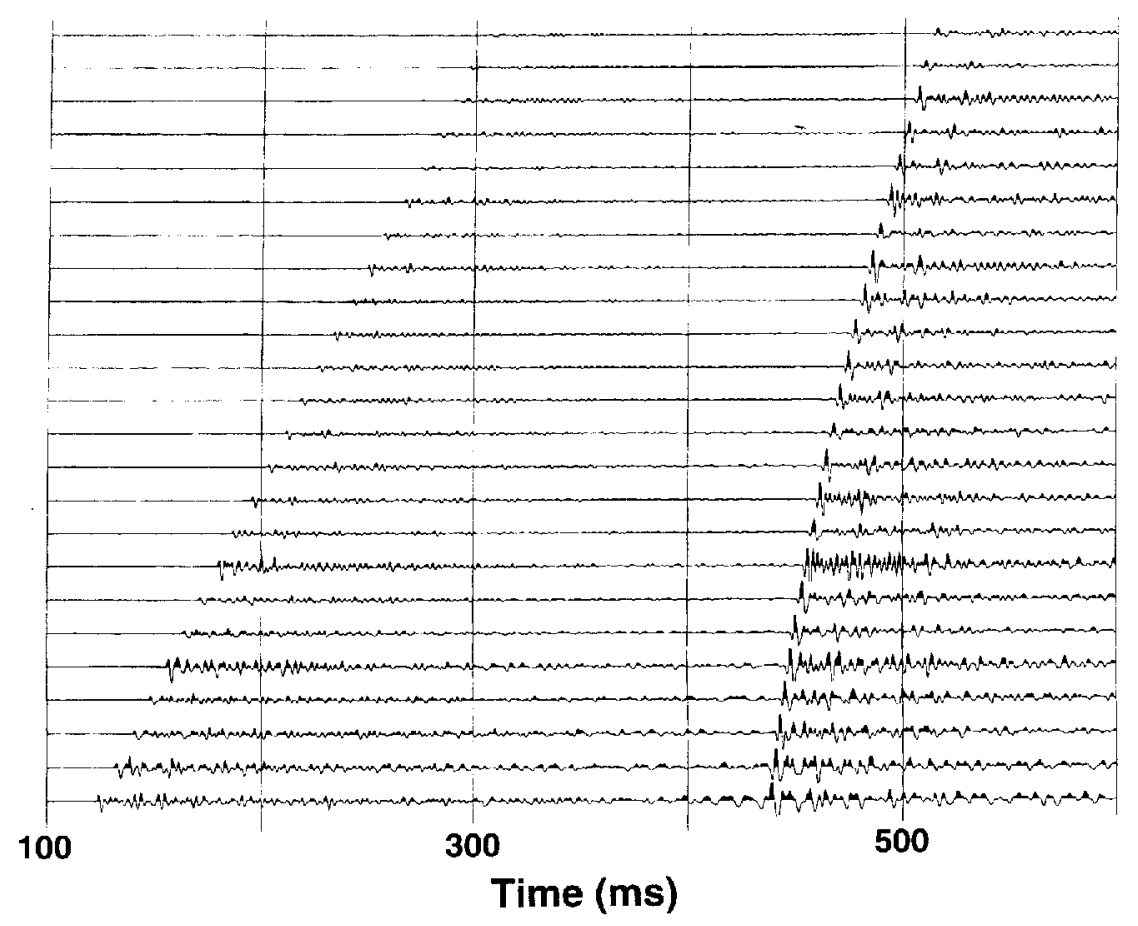

Fig. 3. Seismogram showing reflections at Z20160. Shot-detector offsets: $360-1050 \mathrm{~m}$. On this and succeeding seismograms, each horizontal line shows the ground motion detecled by one of a linear array of seismometers. Upreard deflection of the trace is indicative of upward motement of the ground. Time increases from left to right. The first signal to appear is the direct $P$ wave through the ice; the second strong signal, a fewe hundred milliseconds later, is the reflection from the bed. Note in this case that the first motion in the direc $P$ wave is upward, whereas that in the reflection is downward, i.e. reversed in phase. 


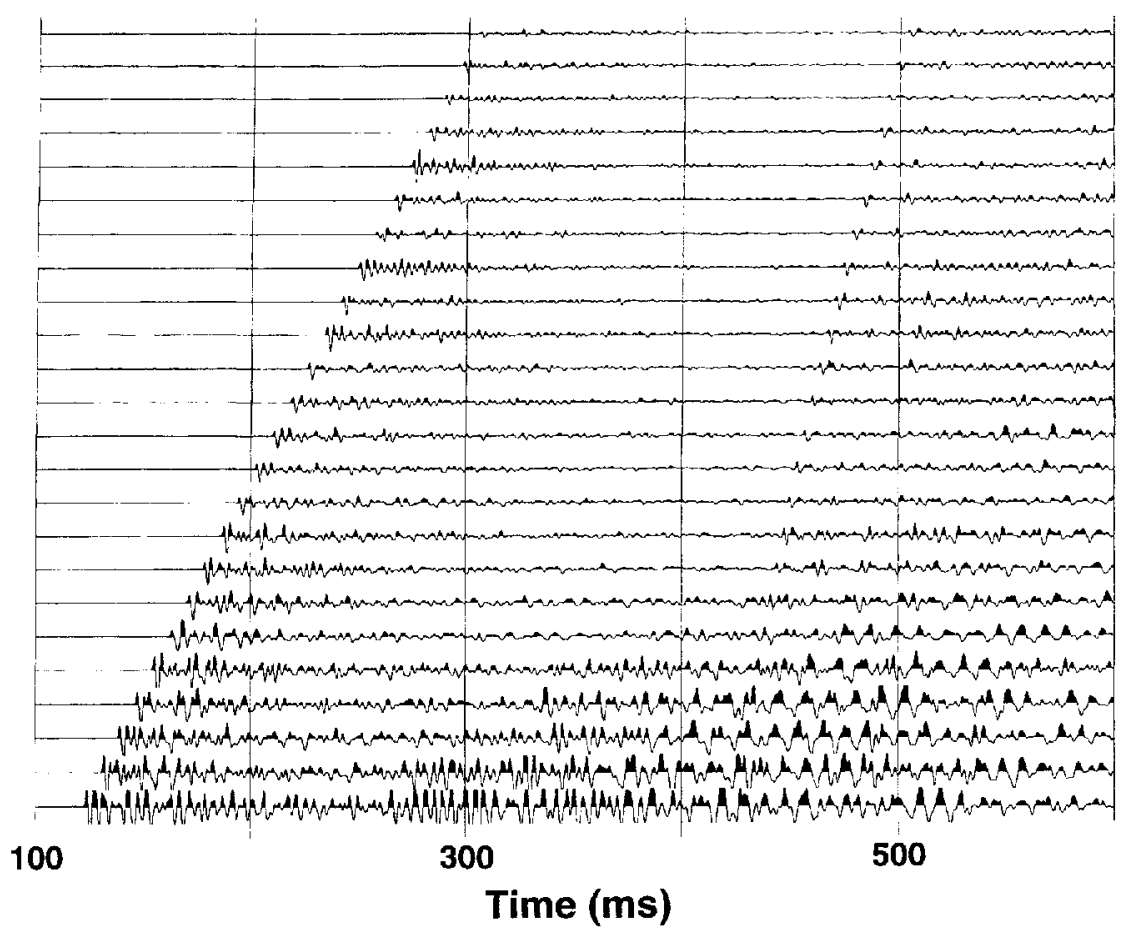

Fig. 4. Seismogram showing reflections at 233120 . Shot-detector offsets: $360-1050 \mathrm{~m}$. Here, the furst motion is upward in both the direct wave and the reflection, i.e. the phase is unreversed.

seen in Figure 3, $20 \mathrm{~ms}$ after the basal reflection, is the "ghost" of the basal reflection, produced by the wave first reflected off the ice surface above the shot. It is clear on most traces that the ghost, which undergocs a phase reversal at the free surface, is unreversed in phase. This means that it has becn reversed twice, which again indicates phase reversal at the bed.

An example of an unreversed-phase basal reflection (with reversed-phase ghost) is shown in Figure 4. This indicates a "high-impedance" bed, which characterizes about half of the area surveyed.

\section{REFLECTION AMPLITUDES}

Since we do not have an absolute calibration of reflection amplitudes, we should like to use amplitude ratios relative to the direct $\mathrm{P}$ wave. But the direct $\mathrm{P}$ wave, unfortunately, is a poor standard to use at DnB, since it is often drastically attenuated by interference from crevasses. This can cause small amplitudes (Fig. 3), a large irregularity from trace to trace (lig. 3), and/or an abrupt diminution in amplitude beyond a paricular distance (Figs 5a and 6). Consequently, amplitude ratios are quantitatively unreliable. However, it is still possible to make some general observations about reflection amplitudes, because they vary so greatly compared with variations that are likely to occur from olher causes considering the uniformity of charge size, shot-hole depth and gain.

\section{OBSERVATIONS}

There are scveral observations that we can make about the characteristics of the reflections. Wc have chosen screral sample seismograms to illustrate our points.
1. The entire survey is characterized by frequent spatial switches between a low-impedance bed and a high-impedance bed (Fig. 7). Fach bed type covers about half of the region.

2. There is agreement in phase on records on the $Z$ line and the transverse lines near their crossing points (Fig. 5).

3. Reflectivity varies more rapidly across flow than parallcl to flow. Half the records from the transverse profiles show marked changes in amplitude across the spread, compared with only onc-tenth of those on the $Z$ line. 'L'his is true of both reversed-phase and unreversed-phase reflections.

4. The reversed-phase and unrcversed-phasc zones can be correlated between the $Z$ line and the transverse lines. Two different corrclations are possible; one of those, which we prefer, yiclds stripes of reversed and unreversed phase that are quasi-parallel to flow (Fig. 7). (The other correlation would yield stripes at about $60^{\circ}$ to flow; such an orientation would be difficult to explain.)

5. The unreversed-phase reflections are fairly weak, with reflection-10-direct-P-wave ratios of 1 or less (Fig. 4). By contrast, the reversed-phase echoes vary widely in strength, from undetectable (Fig. 6) to several times as large as direct $\mathrm{P}$ wave (Fig. 5). In several cases, a largc change takes place within a single record (Fig. 6), although we have not found a clear switch between reversed and unreversed in a single rccord. 


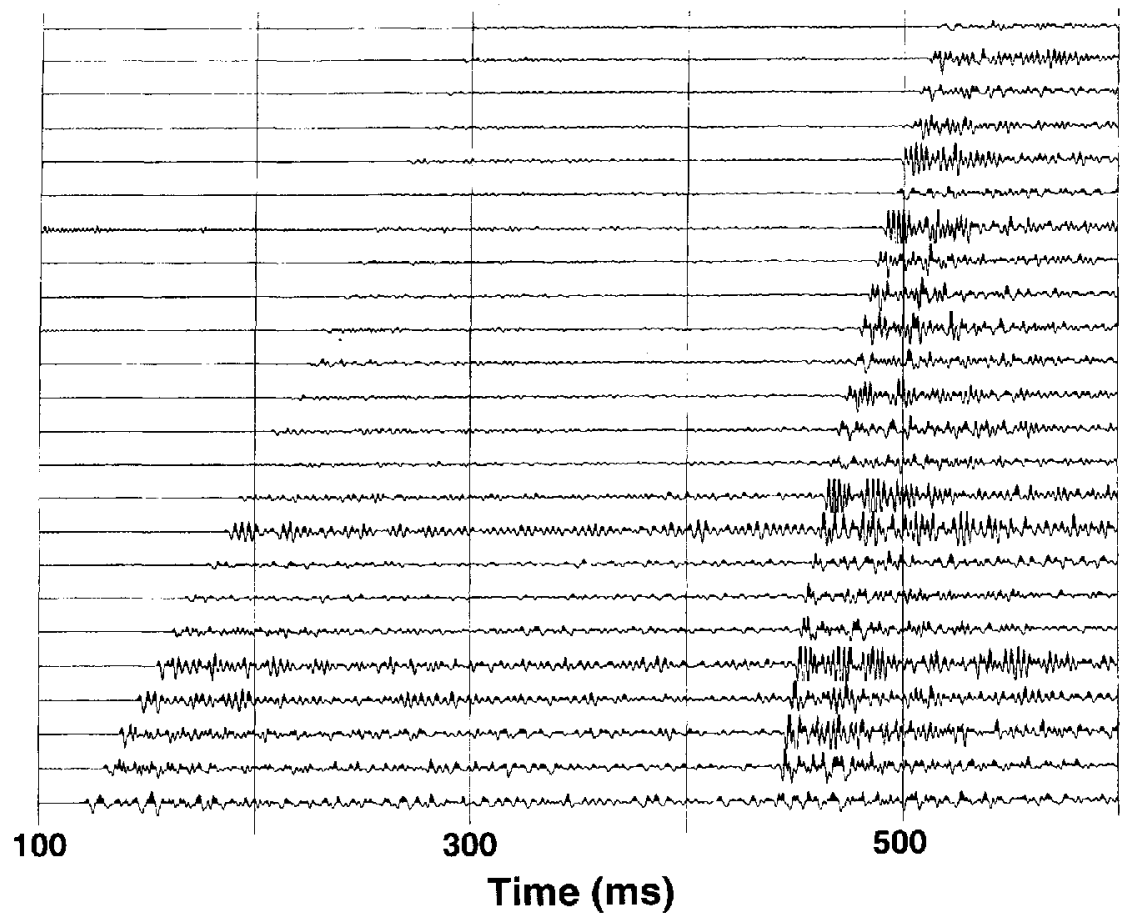

a

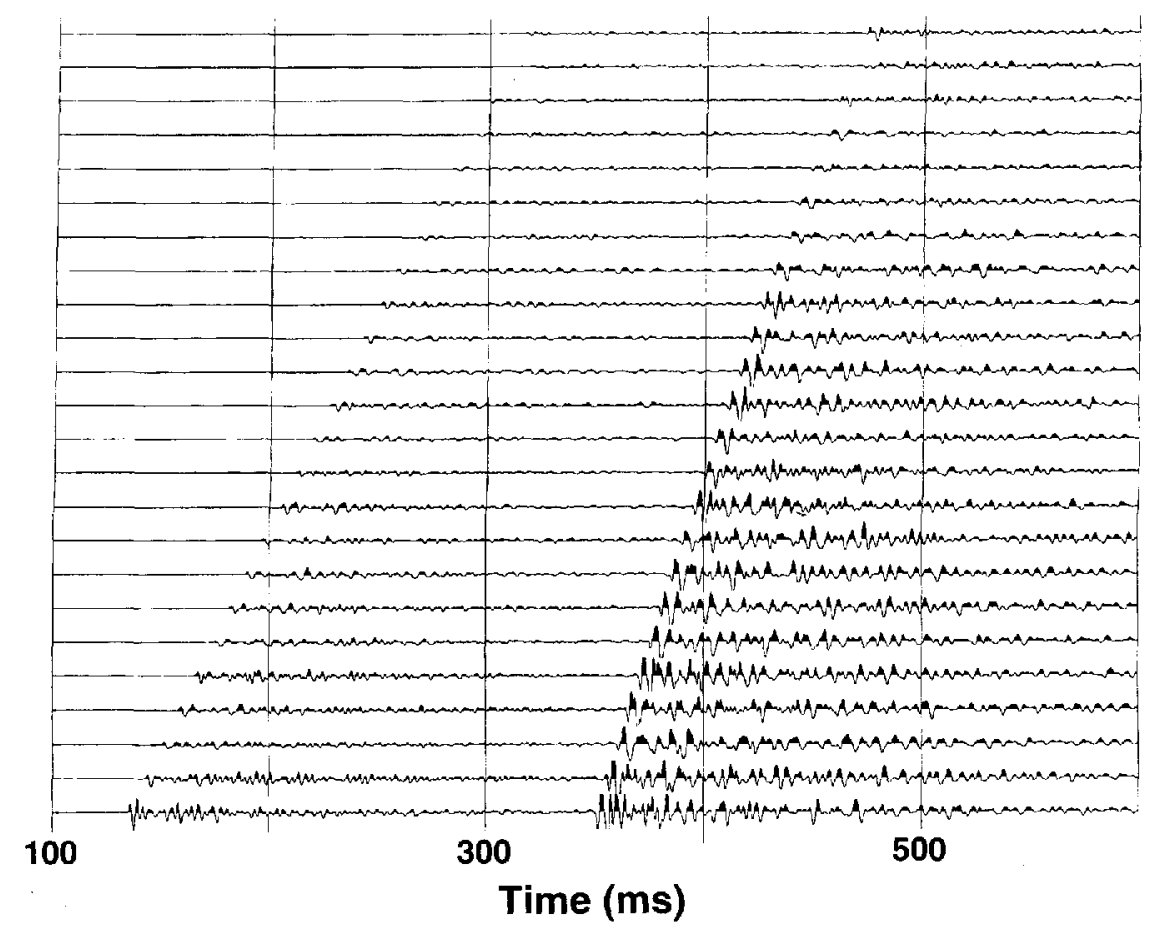

b

Fig. 5. Seismograms from shots at the intersection of the $V$ and Zlines (V1800 and Z4320). a. Recording along the Zline. Shot-detector offsets: $360-1050 \mathrm{~m}$. b. Recording along the V line. Shol-deteclor offsets: $1080-1770 \mathrm{~m}$.

\section{DISCUSSION}

At $\mathrm{UpB}$ and $\mathrm{UpC}$, the principal profile lines were transverse to the direction of ice movement ("flow"). We concluded that changes from "low impedance" to "high impedance" probably arose from changes in the nature of the sedimentary component of the subglacial dilated till (Atre and Bentley, 1993). That would imply that the reflection phase should be more consistent from record to record along the ice stream than across it, bccause sediments of the same type should be dragged into stripes parallel to flow by the icc-induced deformation of the till. Evidence from the secondary lines at $\mathrm{UpB}$ and $\mathrm{UpC}$, which ran parallel to flow, supported this idea but the lines were too short to produce a convincing test. Here, the long line is at a small angle (18 ) to flow and the observations do indeed support the model (observations $1-4)$. 


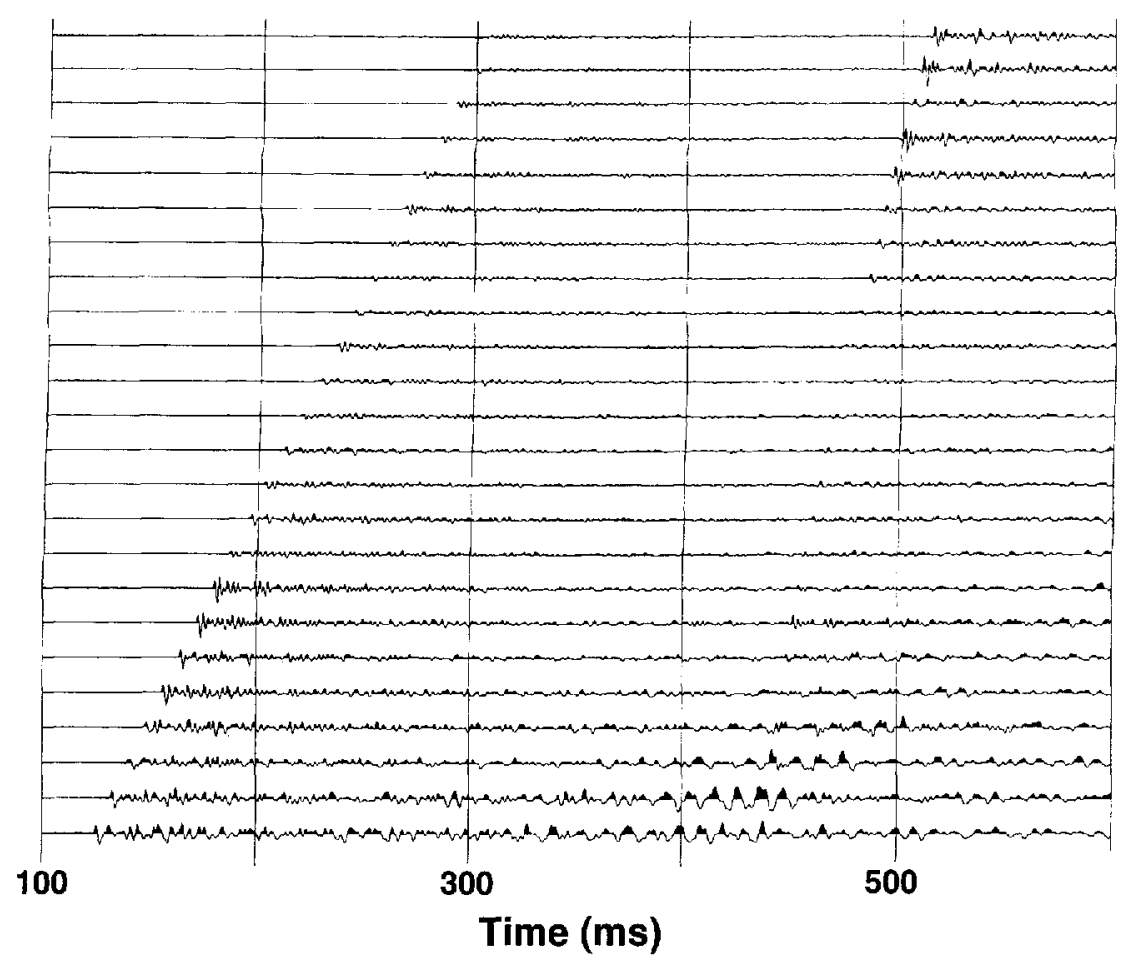

Fig. 6. Seismogram showing reflections at 223400 . Shot-detector offsets: $3601050 \mathrm{~m}$. Note that the reflection virtually disappears on sume traces.

Our previously developed model for unreversed phases at UpB also implied that they would necessarily be fairly weak, because the high porosity of the bed, $\sim 0.40$ (Blankenship and others, 1987; Kamb and Engelhardt, 1991), was inconsistent with an acoustic impedance in the bed much larger than that in the ice Fig. 8). That implication is borne out here (observation 5). On the other hand, there would be no such limitation for reversed-phase reflections, because there is no necessary limit on the proportion of water present at the bed. In fact, we believe it likely the stronger reflections (observation 5) arise from pooled water under the ice. As the acoustic impcdance of water is only about $1.4 \times 10^{6}$ $\left(\mathrm{kg} \mathrm{m}^{-2} \mathrm{~s}^{1}\right)$, less than half that of ice, water at the bed could easily produce an acoustic-impedance contrast with the ice that is an order of magnitude larger than the contrast between ice and till. The acoustic impedance would depend upon the thickness of the water layer.) The occurrence of free water beneath the ice on the ice plain would not be surprising (Alley and others, 1987).

\section{CONCLUSION}

Seismic reflection profiling on the ice plain of Ice Strcam $B$ reveals an ice--bed interfacc that varies laterally in

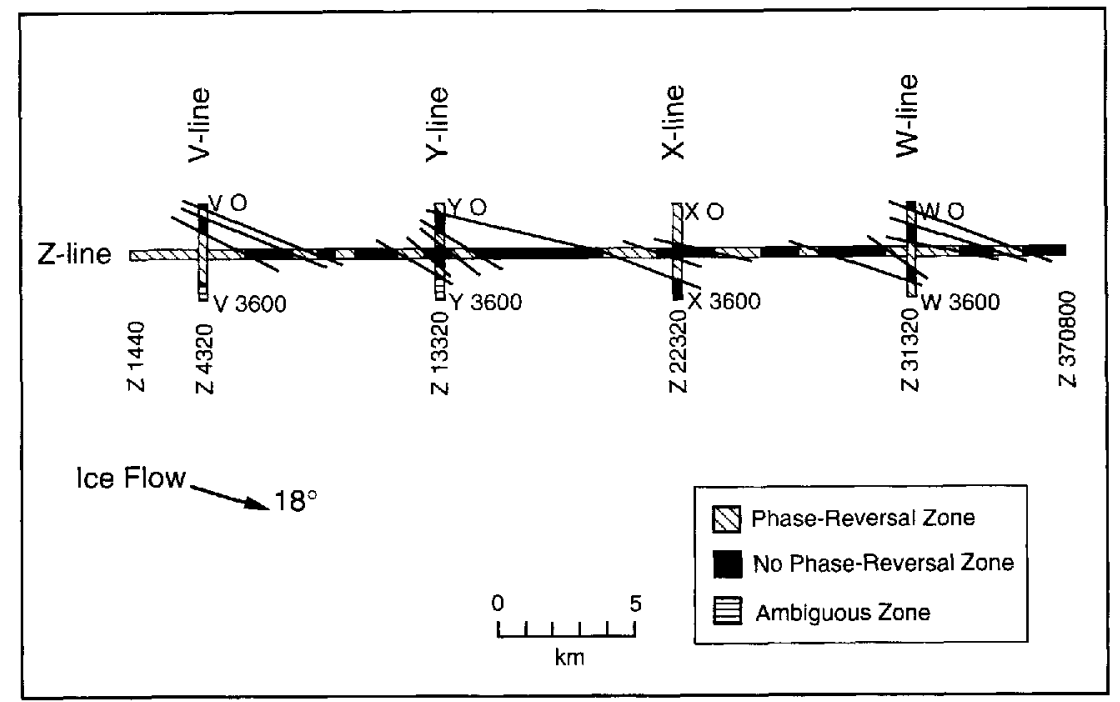

Fig. 7. Diagram of the seismic survey lines at DnB showing the reversed-phase and unreversed-phase zones. Short straightline segments are drawn to show our preferred correlations between zones. The arrow shows the direction of ice movement. 


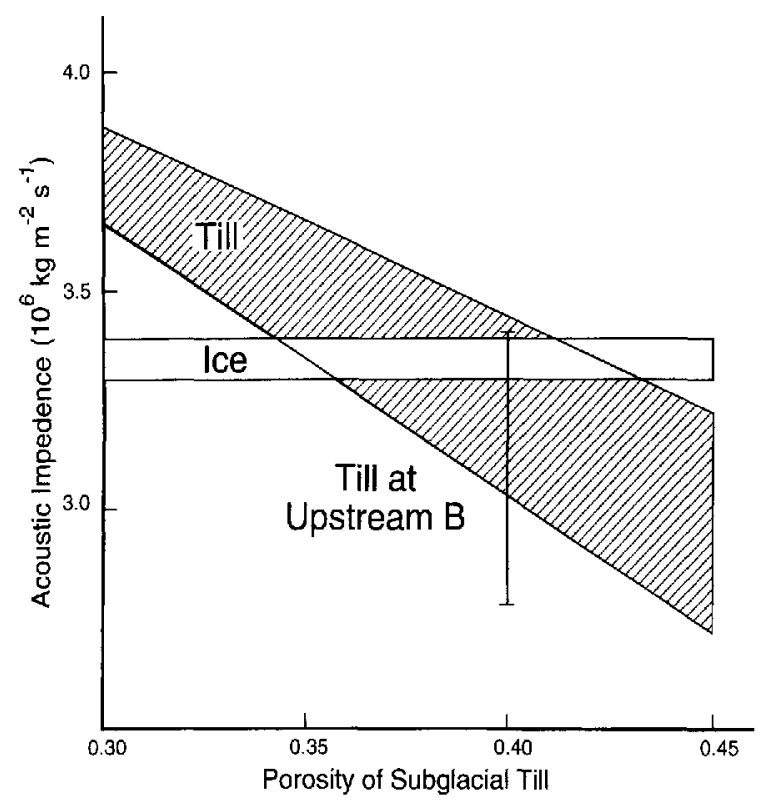

Fig. 8. Acoustic impedance versus porosily for ice and lill. The vertical line shows the range of possible values at UpB. (From Atre and Bentley, 1993.)

acoustic ratio between greater than 1 and less than 1, just as found before beneath the trunks of Ice Streams $B$ and C. A previously developed model that explains the variability in terms of lateral changes in the nature of the subglacial deforming till is supported by the observations at Downstream B. In addition, there is good evidence of pooled water beneath the ice in this boundary region between the ice stream and the ice shelf.

\section{ACKNOWLEDGEMENTS}

We thank S. T. Rooney, D. D. Blankenship, N. Lord, S. Anandakrishnan, J. Kempf and L. Powell, who conducted the field work on Ice Stream B, and personncl of the Polar Icc Coring Office, University of Alaska, for their efficient preparation of the scismic shot holes. This research was supported by U.S. National Science Foundation grant DPP86-14011. This is contribution No. 542 of the Geophysical and Polar Research Center, University of Wisconsin-Madison.

\section{REFERENCES}

Alley, R. B., D. D. Blankenship, G. R. Bentlev and S. T. Roonty 1987. Till beneath Ire Stream B. 4. A coupled ice-till flow model. f. Geophy. Res, 92(B9), 8931-8940.

Atre, S. R. 1990. Seismic studies over Icc Strcam C. West Antarclica. M.S. thesis, Cniversity of Wisconsin-Madison.

Atre, S. R. and C. R. Bentley. 1993. Laterally varying basal conditions beneath Ice Streams B and C, West Antarctica. f. Craciol. 39 133: 507514.

Blankenship, D. 1), C. R. Bentley, S. T. Rooney and R. B. Alley. 1987. Till beneath Ice Stream B. 1. Propertics derived from seismic travel times. 7. Geophys. Res., 92(B9). 89038911.

Kamb, B. and H. Engclhardt. 1991. Antarctic Ice Stream B: conditions controlling its motion and interactions with the climate system. Intemational Association of Hydralogical Sciences Publication 208 isymposium at St. Petersburg, September 1990 Ghariers-acean-atmosphere intertations). $145-154$.

Rooney, S. T. 1988. Subglacial geology of Ice Strcam B, West Antarctica. (Ph.D. thesis, University of 11 iscomsin-Madison.)

Romey, S. T., 1). 1). Blankenship, R. B. Alley and C. R. Bentley 1987. Till beneath Ice Stream B. 2. Structure and continuity. J. Ceophrs. Res., 92(B9), 89138920.

The accuracy of references in the text and in this list is the responsibility of the authors, to whom queries should be addressed. 